\title{
Identification of roofing materials with Discriminant Function Analysis and Random Forest classifiers on pan-sharpened WorldView-2 imagery - a comparison
}

\author{
DÁvid ABRIHA ${ }^{1}$, Zoltán KOVÁCS ${ }^{1}$, SARAwUt NINSAWAT², LÁsZló BERTALAN ${ }^{1}$ \\ BoglárKa BALÁZS ${ }^{1}$ and SZILÁrd SZABÓ ${ }^{1}$
}

\begin{abstract}
Identification of roofing material is an important issue in the urban environment due to hazardous and risky materials. We conducted an analysis with Discriminant Function Analysis (DFA) and Random Forest (RF) on WorldView-2 imagery. We applied a three- and a six-class approach (red tile, brown tile and asbestos; then dividing the data into shadowed and sunny roof parts). Furthermore, we applied pan-sharpening to the image. Our aim was to reveal the efficiency of the classifiers with a different number of classes and the efficiency of pan-sharpening. We found that all classifiers were efficient in roofing material identification with the classes involved, and the overall accuracy was above 85 per cent. The best results were gained by RF, both with three and with six classes; however, quadratic DFA was also successful in the classification of three classes. Usually, linear DFA performed the worst, but only relatively so, given that the result was 85 per cent. Asbestos was identified successfully with all classifiers. The results can be used by local authorities for roof mapping to build registers of buildings at risk.
\end{abstract}

Keywords: remote sensing, pan-sharpening, asbestos, machine learning

\section{Introduction}

We are witnessing the increasing relevance of remote sensing in all areas of life. The first applications aimed at the analysis of land use and land cover (LULC), and then, parallel with the wider palette of satellite and aerial images, the detection of changes became the focus of research (Szabó, S. et al. 2016; Gulácsi, A. and Kovács, F. 2018). The geometric resolution of images has improved from $80-100 \mathrm{~m}$ to about $1 \mathrm{~m}$ over the last 30-40 years; furthermore, there are images (e.g. Landsat and Sentinel) which can be obtained for free. Another tendency is the increase in thematic resolution due to the larger number of spectral bands. Consequently, while first studies attempted to classify aggregated land cover classes (e.g. forests, grasslands or artificial surfaces), nowadays it is possible to produce species-level habitat maps (Burai, P. et al. 2015, 2016; DeÁK, M. et al. 2017).

Beside LULC mapping new research targets have emerged with the improved possibilities of remotely sensed data. One of these new areas is the mapping of roofing materials (NAGYváradi, L. et al. 2011; Mucsi, L. et al. 2017). The topic has its relevance from various perspectives: materials can be flammable (wooden, hay) or can be risk factors of 'carcinogenicity' (asbestos). In this study we focus on traditional roofing materials and asbestos (Cilia, C. et al. 2015; WiLK, E. et al. 2015;

\footnotetext{
${ }^{1}$ Department of Physical Geography and Geoinformatics, University of Debrecen, Debrecen, Hungary. Correspondent author's e-mail: szabo.szilard@science.unideb.hu

${ }^{2}$ Department of Remote Sensing and Geographic Information Systems (RS-GIS), Asian Institute of Technology, Bangkok, Thailand.
} 
Gibril, M.B.A. et al. 2016; KRówczyńsKA, M. et al. 2016). Asbestos mapping has a wide literature, and several authors have attempted to identify this dangerous type of roofing. If the material is damaged or weathered, asbestos causes diseases such as asbestosis, mesothelioma or lung-cancer, due to its microfiber content (Mándi, A. et al. 2000; PetjA, P.M. et al. 2010). Most municipalities have to face this environmental issue, but, even at settlement-level, comprehensive inventories do not exist; therefore, a supervised classification of remotely sensed images with an appropriate accuracy assessment provides an accessible alternative (COMBER, A. et al. 2012).

Roof mapping uses both aerial photographs and satellite images. While aerial surveys are usually conducted at an altitude of 1-6 km with 10-50 cm geometric resolution, satellite images are taken at $700-800 \mathrm{~km}$ with a coarser $(2-30 \mathrm{~m})$ resolution. In addition, quantum (photon) energy is in inverse ratio to the wavelength, which means that sensors have to scan larger areas for larger wavelengths to collect reliable data from the surface. Accordingly, panchromatic (a single spectral band with 400-500 nm bandwidth) bands always have finer resolution than narrow multispectral bands (in the case of Landsat satellites the geometric resolution of the panchromatic band is $15 \mathrm{~m}$, while the multispectral bands are $30 \mathrm{~m}$ ). Geometric resolution is a limiting factor when using satellite images: if a pixel is larger than a potential house, its pixel values mix with the pixel values of the surrounding environment and the image cannot be used for this purpose. A potential solution can be to apply the pan-sharpening method, when we improve the geometric resolution of the multispectral bands with the finer resolution of the panchromatic band. The procedure distorts the spectral profiles of the objects, but improves the spatial characteristics (YuHENDRA, Alimuddin, I. Y. et al. 2012).

Previous studies have applied aerial hyperspectral images of different sensors (APEX, AISA, MIVIS; TAherzadeh, E. and Shafri, H.Z.M. 2013; KsıĄżeK, J. 2014; Szabó, S. et al. 2014) and satellite images (WorldView;
Taherzadeh, E. and Shafri, H.Z.M. 2013; TAHERZADEH, E. et al. 2014; SAMSUdin, S.H. et al. 2016) and have had different degrees of success in the identification of the roof types. We aimed to reveal whether pan-sharpening can improve the classification results when using a WorldView-2 satellite image. Fine resolution raises the question of the inhomogeneous reflectance of small surfaces: roof segments with different irradiation status; i.e. those in the sun and those in the shade. We distinguished between these roof segments and studied the efficiency of this kind of reference data collection.

\section{Materials and methods}

We performed our investigations in Debrecen, which is the second largest city in Hungary (Figure 1). Its population is 203,000 and has various built-in areas, ranging from blocks of flats to detached houses with gardens. We selected an area where the roofing materials were diverse and contained asbestos.

\section{Datasets and reference data}

We applied a WorldView-2 (WV2) satellite image. WV2 operates at a $770 \mathrm{~km}$ altitude and has eight multispectral bands (coastal blue [400-450 nm], blue [450-510 nm], green [510-580 nm], yellow [585-625 nm], red [630-690 nm], red-edge [705-745 nm] and two near infrared [770-895 and 860-1,040 $\mathrm{nm}]$ ) with a $2 \mathrm{~m}$ geometric resolution and a panchromatic band (450-800 nm) with a $0.5 \mathrm{~m}$ resolution. The image was captured at 24.07.2016 without cloud cover.

Three types of roofing types were collected: red tile, brown tile and asbestos. Red and brown tiles were both concrete tiles, the only difference was their color, and both types are popular in Hungary. Asbestos roofing was also popular due to its low price; furthermore, it has an indisputable advantage: resistance to heat and fire (KANG, D. et al. 2013). However, this material is a serious threat to health and both production and use has 


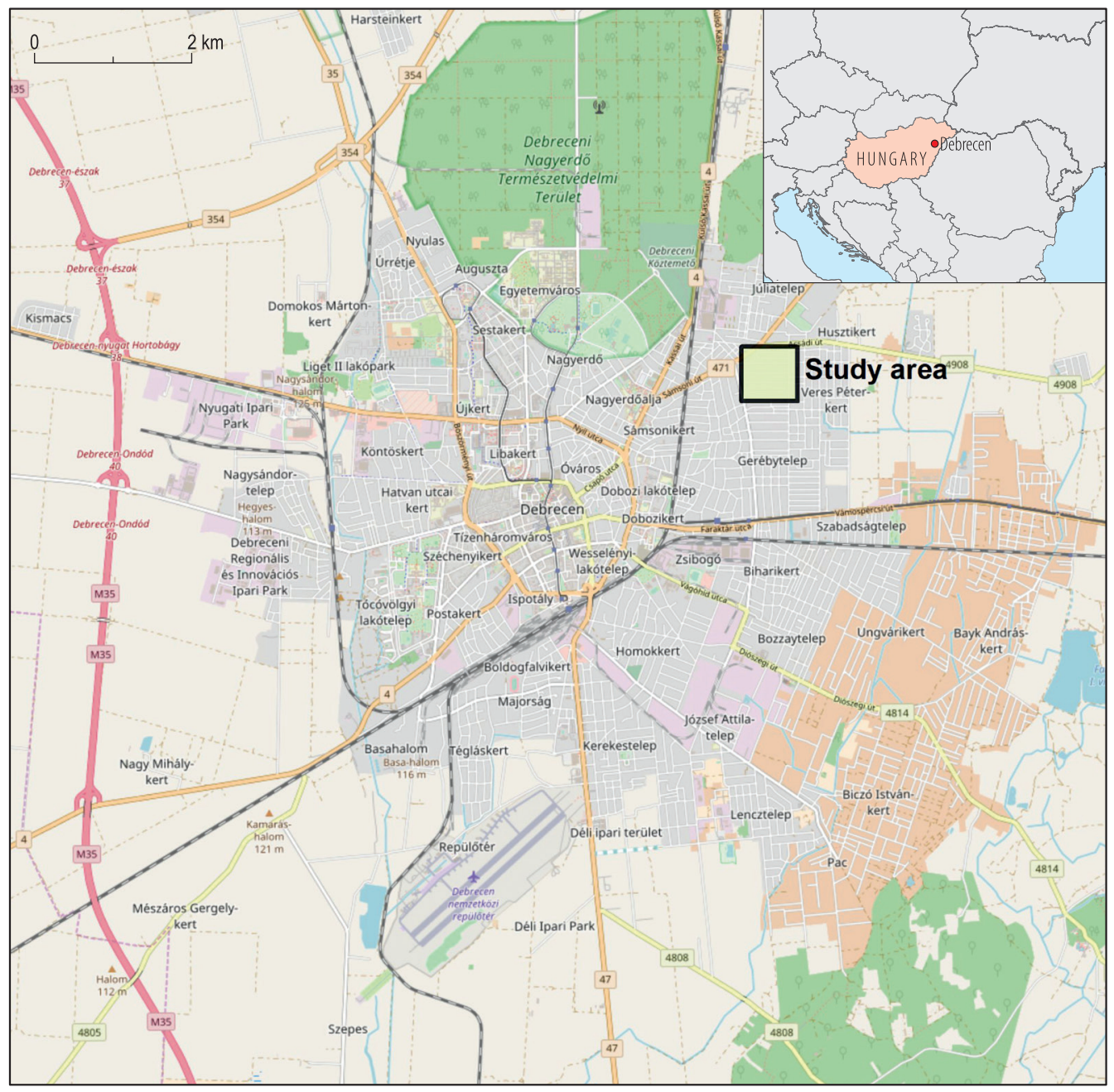

Fig. 1. Location of the study area

been banned in Hungary since 2005 (decree 41/2000 EüM-KöM).

We collected the roofing types of 350 houses as ground truth (reference) data in a field survey using a Stonex S9 RTK GPS. Later, in the GIS Laboratory, we assigned the roofs to the types observed in the field in ENVI 5.3 software (Harris Geospatial Solutions, 2017). We discriminated the different segments of the roofs considering the irradiation based on visual interpretation of the satellite im- age's panchromatic band. During the classifications, we intended to test whether the application of three categories or six categories (with the sunny and shadowed segments) were more efficient.

We conducted pan-sharpening with the panchromatic band fusing with the lower resolution multispectral bands: GramSchmidt method (Maurer, T. 2013) in ENVI 5.3 software (Harris Geospatial Solutions, 2017) was applied. 


\section{Image classification}

We classified the images using two approaches. Firstly, we applied the traditional multivariate statistical classification method, the Linear Discriminant Function Analysis (LDFA) and Quadratic Discriminant Function Analysis (QDFA). This approach is an ordination (dimension reduction) technique which substitute the original variables (i.e. bands) with discriminant function (DF) scores. The resulting DF scores are derived along new axes to maximize the discrimination among the a priori groups (i.e. we have prior knowledge on the groups as reference data unlike in case of other ordination techniques such as Principal Component Analysis; Podani, J. 2000). DFs are calculated in the m-dimensional space defined by the input variables $(\mathrm{m}-1 \mathrm{di}-$ mension, where $\mathrm{m}$ is the number of a priori categories; i.e. roof types) based on "decision boundaries", depending on the input reference data (i.e. a priori groups). Decision boundaries or surfaces can be defined with linear or quadratic functions (THARwAT, A. 2016).

As we used more than two categories in the classification, the applied method is called multiple or "Canonical" Discriminant Function Analysis (but we did not apply it in the nomenclature). DFA supposes multivariate normality, homogeneity of covariance matrices (note: QDFA allows that issue) and, similarly to regression, is sensitive to multicollinearity (nevertheless, some researchers have found DFA to be robust when assumptions were violated; Stevens, J. 1996) and outlier data. It is not a common image classification technique and we intended to examine how efficient the usage of these approaches might be.

In contrast to this, the classifier applied, the Random Forest (RF) is a robust machine learning technique, and has no prerequisites regarding distribution or the variables involved (Ho, T.K. 1995; PAL, M. 2005; PÁsztor, L. et al. 2015). $\mathrm{RF}$ is calculated from a large number of decision trees: in our study 500 decision trees were generated. Data was taken from the training dataset with a random selection for each decision tree; the number of variables involved was the square root of the number of the possible maximum: in our case we had 8 bands; thus, the algorithm also used 2 variables in each tree applying random selection (BREIMAN, L. 2001; Louppe, G. et al. 2013). A critical remark can be, that according to the random sampling, each run of the algorithm provides (slightly) different outcomes; i.e. the reproducibility can be an issue. Although it is true for lots of software implementations, it can be eliminated if the parameters of random sampling are also fixed such in case of $\mathrm{R}$ software.

We applied a building-mask layer which was produced with the help of the NDVI (Normalized Difference Vegetation Index, Rouse, J.W. et al. 1974) values $(<0.1)$ and a normalized digital surface model $(>3 \mathrm{~m})$, which was derived from the Digital Terrain Model and the Digital Surface Model using a LiDAR survey conducted in 2013. Thus, all misclassifications concerning the non-building areas were omitted.

In order to hold the conditions constant for all classifications, we did not apply variable selection, all bands were involved for all models.

Summary of data procession is presented in Figure 2. Image classification was performed in R 3.4 (R Core Team, 2018) with the caret (KunN, M. et al. 2018; model building and evaluation), MASS (VenAbles, W.N. and RIPLEY, B.D. 2002; LDFA and QDFA classification), rpart (TherneAu, T. and AtKInson, B. 2018; RF classification) and tidyverse (Wiскнам, H. 2017; data preparation) packages; and, for the visualization we used the raster package (HiJMAns, R.J. 2017).

\section{Accuracy assessment}

Accuracy assessment was carried out with the reference data: we separated the reference dataset into training and testing subsets in an 80-20 per cent ratio with random selection. We used the confusion matrix for the evaluation of the classification results (Table 1). We reported overall accuracy (OA; Eq. 1), precision (Eq. 2), sensitivity (True Positive Rate; Eq. 3) and specificity (True Negative Rate; Eq. 4; Powers, D.M.W. 2007). 


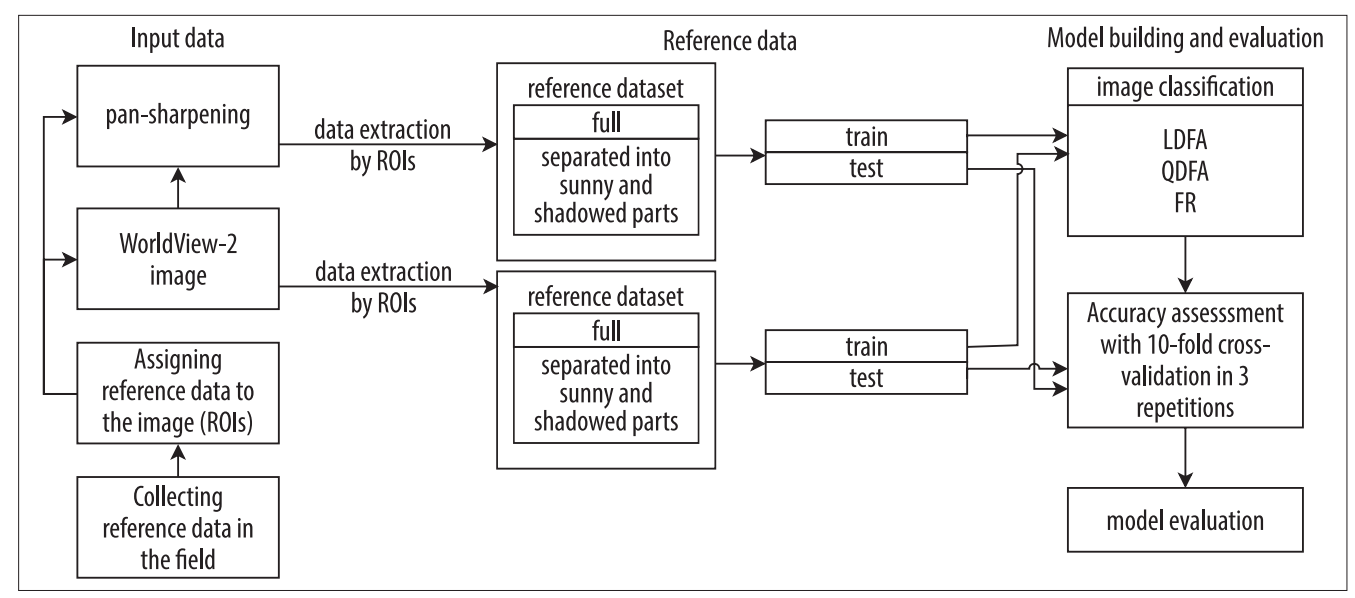

Fig. 2. Workflow of the data preparation and image classification

These equations concern the binomial approach, but we had three and six classes to predict. Therefore, we applied the "one vs. all" approach: we calculated the indices for one class to all other classes (Kassambra, A. 2018). These indices differ from the common and widely known approach of Congalton, R.G. (1991), but we intended to provide a deeper analysis of the thematic accuracy.

We applied resampling with a 10-fold cross-validation to estimate the statistical parameters of OA and used the 95 per cent confidence interval to describe the uncer- tainty of the outcomes. We split the training dataset into 10 subgroups and used 9 at a time to train and test on 1 ; the procedure was then repeated until all subgroups were used as a test dataset. Finally, the whole procedure was repeated three times. Thus, statistical parameters were derived from a resampling dataset of 30 elements for each classification algorithm (Kassambra, A. 2018). Accuracy assessment was performed in R 3.4 with the caret package (KuHN, M. et al. 2018) following the methodology of BRownleE, J. (2016).

Table 1. A confusion matrix with explanations

\begin{tabular}{l|l|l|l}
\hline \multirow{2}{*}{ Predicted } & Total population & \multicolumn{1}{|c}{ Observed } \\
\cline { 2 - 4 } & Negative & $\begin{array}{l}\text { Negative } \\
(\mathrm{TN})\end{array}$ & \multicolumn{1}{c}{ Positive } \\
\cline { 2 - 4 } & Positive & $\begin{array}{l}\text { False positive/false discovery } \\
(\mathrm{FP})\end{array}$ & $\begin{array}{l}\text { True positive/correct discovery } \\
(\mathrm{FP})\end{array}$ \\
\hline Accuracy $(O A)=\frac{T P+T N}{T P+T N+F P+F N}$ & Eq. 1. \\
\hline Precision $=\frac{T P}{T P+F P}$ & Eq. 2. \\
\hline Sensitivity $=\frac{T P}{T P+F N}$ & Eq. 3. \\
\hline Specificity $=\frac{T N}{T N+F P}$ & Eq. 4. \\
\hline
\end{tabular}




\section{Results}

\section{Pixel values and satellite bands}

Coastal blue and blue bands (B1, B2) were not appropriate to identify the roofing types, as their range of the pixel values were similar. The green band (B3) was the first band which made a limited differentiation possible, but asbestos and red tiles were still similar. However, from the electromagnetic range of the yellow band (B4; from $585 \mathrm{~nm}$ ), all the three types of roofing materials had a distinct range of pixel intensity values (Figure 3). The discrimination of the sunny and shadowed roof planes caused more overlap between the pixel intensity ranges (Figure 4). B1 and B2 bands were still very similar, and the different irradiation segments did not help to distinguish them. A common feature of the similarity was that the shadowed segments of asbestos were very similar to the sunny segments of brown tiles in almost every band, except for the B8 band, where the shadowed segments of red tiles were similar to this class.

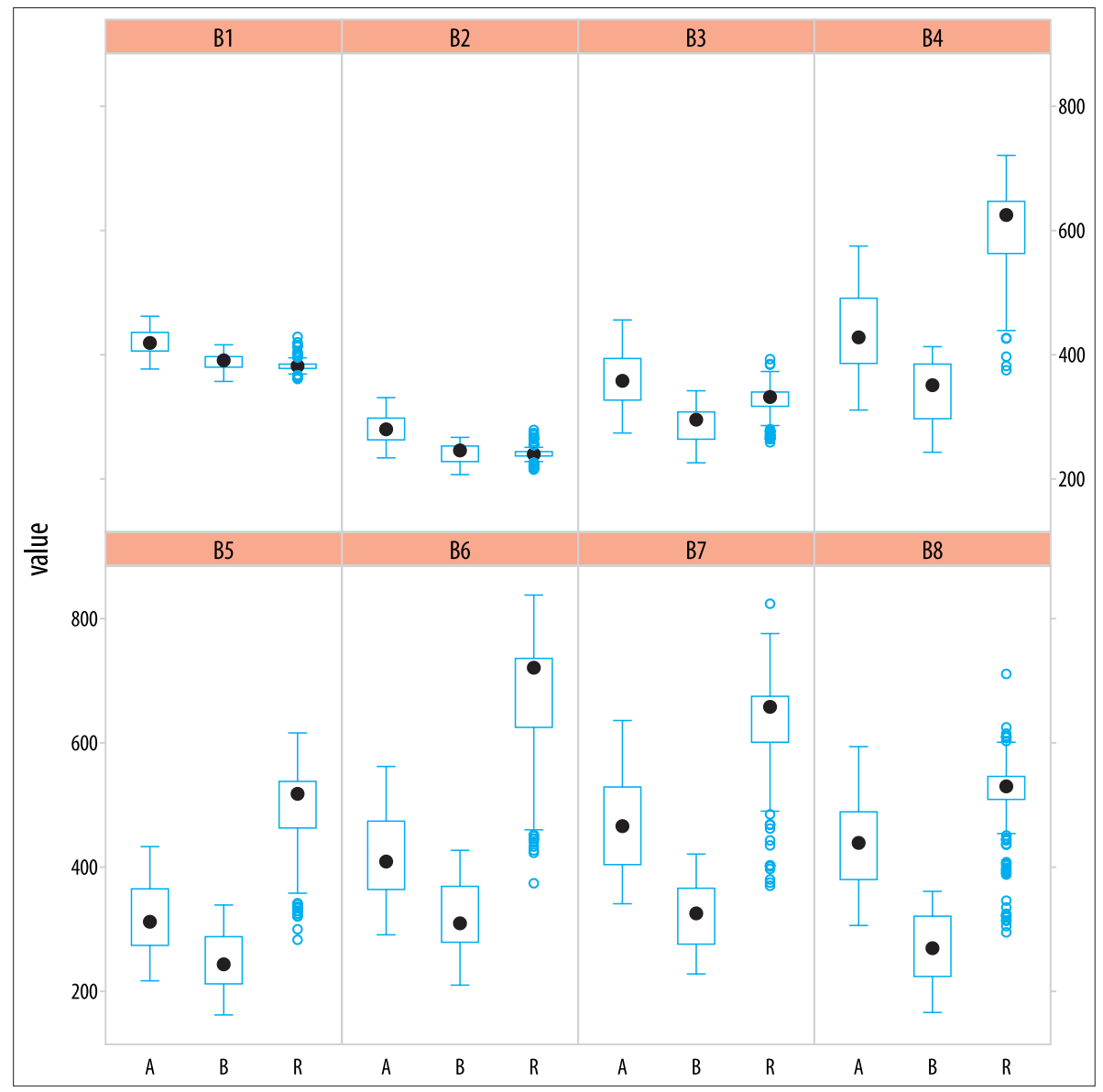

Fig. 3. Pixel value distribution of the roofing materials by bands (B1-B8) of WV-2 using three classes. $\mathrm{A}=$ asbestos; $\mathrm{B}=$ brown tile; $\mathrm{R}=$ red tile 


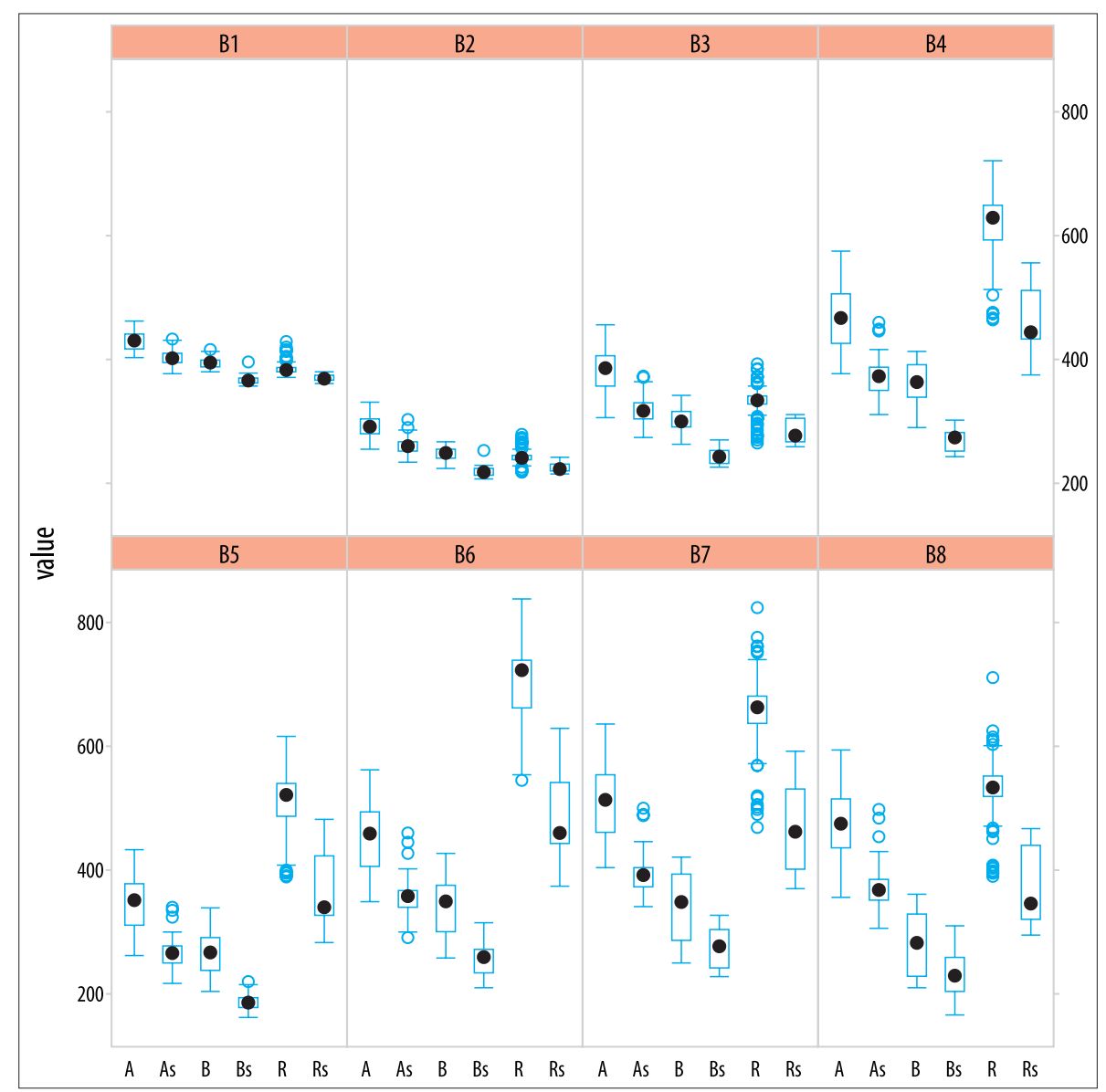

Fig. 4. Pixel value distribution of the roofing materials by bands (B1-B8) of WV-2 using six classes. $-\mathrm{A}=$ asbestos; $\mathrm{B}=$ brown tile; $\mathrm{R}=$ red tile; As, Bs, Rs = A, B and R with shadowed subclasses, respectively

\section{Evaluation of the classification performance}

Classifications provided the maps of the roofing materials (Figures 5 and 6) with varying accuracy and reliability. Although RF classifier seemed more reliable visually, we evaluated the results with the indices of accuracy assessment, too.

Generally, LDFA performed the worst, while QDFA and RF provided similar better results, with only a few percentage points of difference (Tables 2 and 3). However, classifications were successful in every case; con- sidering the OA, the worst result was 0.848 and the best 0.996 . All indices of accuracy assessment showed good results; however, there were some lower values, too.

Using the original bands resulted in 2-3 per cent worse OAs compared to the pan-sharpened input data. Besides, indices of class level accuracy also indicated good classifications. In the case of LDFA the improvement with the pan-sharpened images were not obvious because even if there were better results, some others became worse (e.g. precision changed from 0.970 to 0.955 in the case of asbestos). 
Table 2. Accuracy assessment indices of the classification conducted with all original satellite bands with three classes

\begin{tabular}{l|l|c|c|c}
\hline Method & Indicator & Red tile & $\begin{array}{c}\text { Brown } \\
\text { tile }\end{array}$ & Asbestos \\
\hline \multirow{4}{*}{ LDFA } & OA & 0.949 & - & - \\
& Precision & 1.000 & 0.823 & 0.970 \\
& Sensitivity & 0.933 & 1.000 & 0.943 \\
& Specificity & 1.000 & 0.953 & 0.977 \\
\hline \multirow{4}{*}{ QDFA } & OA & 0.974 & - & - \\
& Precision & 1.000 & 0.928 & 0.972 \\
& Sensitivity & 0.966 & 0.984 & 1.000 \\
& Specificity & 1.000 & 0.928 & 0.977 \\
\hline \multirow{3}{*}{ RF } & OA & 0.962 & - & - \\
& Precision & 1.000 & 0.886 & 0.971 \\
& Sensitivity & 1.000 & 0.929 & 0.943 \\
& Specificity & 1.000 & 0.969 & 0.977 \\
\hline
\end{tabular}

Table 3. Accuracy assessment indices of the classification conducted with all pan-sharpened satellite bands with three classes

\begin{tabular}{l|l|c|c|c}
\hline Method & Indicator & Red tile & $\begin{array}{c}\text { Brown } \\
\text { tile }\end{array}$ & Asbestos \\
\hline \multirow{4}{*}{ LDFA } & OA & 0.961 & - & - \\
& Precision & 1.000 & 0.893 & 0.955 \\
& Sensitivity & 0.963 & 0.948 & 0.963 \\
& Specificity & 1.000 & 0.975 & 0.967 \\
\hline \multirow{4}{*}{ QDFA } & OA & 0.995 & - & - \\
& Precision & 0.998 & 0.977 & 1.000 \\
& Sensitivity & 0.989 & 0.995 & 1.000 \\
& Specificity & 0.998 & 0.994 & 1.000 \\
\hline \multirow{4}{*}{ RF } & OA & 0.996 & - & - \\
& Precision & 0.998 & 0.991 & 0.996 \\
& Sensitivity & 1.000 & 0.986 & 0.997 \\
& Specificity & 0.999 & 0.998 & 0.996 \\
\hline
\end{tabular}

Table 4. Accuracy assessment indices of the classification conducted with all original satellite bands with six classes (sunny and shadowed sides of roof planes)

\begin{tabular}{l|l|c|c|c|c|c|c}
\hline Method & Indicator & Red tile & $\begin{array}{c}\text { Red tile in } \\
\text { shadow }\end{array}$ & $\begin{array}{c}\text { Brown } \\
\text { tile }\end{array}$ & $\begin{array}{c}\text { Brown tile } \\
\text { in shadow }\end{array}$ & Asbestos & $\begin{array}{c}\text { Asbestos } \\
\text { in shadow }\end{array}$ \\
\hline \multirow{4}{*}{ LDFA } & OA & 0.848 & - & - & - & - & - \\
& Precision & 1.000 & 0.285 & 0.769 & 1.000 & 0.954 & 0.785 \\
& Sensitivity & 0.814 & 0.666 & 0.909 & 1.000 & 0.913 & 0.916 \\
& Specificity & 1.000 & 0.934 & 0.955 & 0.333 & 0.982 & 0.955 \\
\hline \multirow{4}{*}{ QDFA } & OA & 0.924 & - & - & - & - & - \\
& Precision & 1.000 & 0.600 & 0.833 & 0.666 & 1.000 & 0.9167 \\
& Sensitivity & 0.925 & 1.000 & 0.909 & 0.986 & 0.956 & 0.9167 \\
& Specificity & 1.000 & 0.973 & 0.970 & 0.666 & 1.000 & 0.9851 \\
\hline \multirow{4}{*}{ RF } & OA & 0.886 & - & - & - & - & - \\
& Precision & 1.000 & 0.600 & 0.769 & 1.000 & 0.916 & 0.777 \\
& Sensitivity & 0.963 & 1.000 & 0.909 & 0.666 & 0.956 & 0.583 \\
& Specificity & 1.000 & 0.973 & 0.955 & 1.000 & 0.964 & 0.970 \\
\hline
\end{tabular}

Table 5. Accuracy assessment indices of the classification conducted with all pan-sharpened satellite bands with six classes (sunny and shadowed sides of roof planes)

\begin{tabular}{l|l|c|c|c|c|c|c}
\hline Method & Indicator & Red tile & $\begin{array}{c}\text { Red tile in } \\
\text { shadow }\end{array}$ & $\begin{array}{c}\text { Brown } \\
\text { tile }\end{array}$ & $\begin{array}{c}\text { Brown tile } \\
\text { in shadow }\end{array}$ & Asbestos & $\begin{array}{c}\text { Asbestos } \\
\text { in shadow }\end{array}$ \\
\hline \multirow{4}{*}{ LDFA } & OA & 0.877 & - & - & - & - & - \\
& Precision & 0.959 & 0.833 & 0.897 & 0.788 & 0.935 & 0.653 \\
& Sensitivity & 0.947 & 0.735 & 0.852 & 0.820 & 0.850 & 0.859 \\
& Specificity & 0.979 & 0.990 & 0.981 & 0.990 & 0.976 & 0.933 \\
\hline \multirow{5}{*}{ QDFA } & OA & 0.941 & - & - & - & - & - \\
& Precision & 0.979 & 0.800 & 0.975 & 0.980 & 0.974 & 0.811 \\
& Sensitivity & 0.962 & 0.882 & 0.987 & 0.980 & 0.908 & 0.926 \\
& Specificity & 0.989 & 0.986 & 0.996 & 0.999 & 0.990 & 0.968 \\
\hline \multirow{5}{*}{ RF } & OA & 0.988 & - & - & - & - & - \\
& Precision & 1.000 & 0.985 & 0.987 & 1.000 & 0.977 & 0.979 \\
& Sensitivity & 1.000 & 1.000 & 0.987 & 1.000 & 0.994 & 0.933 \\
& Specificity & 1.000 & 0.999 & 0.998 & 1.000 & 0.990 & 0.997 \\
\hline
\end{tabular}


However, in the case of QDFA and RF the decrease in the indices was only between 1-2 per cent, although the increase was more than 10 per cent (e.g. in the case of brown tile, precision increased from 0.886 to 0.991 ).

When we discriminated the roof segments based on the irradiation, the thematic accuracy reflected the observations reported in the previous section: the higher number of classes caused lower OA values (Tables 4 and 5). LDFA had the weakest performance with its $0.848 \mathrm{OA}$ value, while QDFA provided a very efficient solution (OA: 0.924) with the original bands. However, the accuracy improved by 10.2 per cent for RF when we applied the pansharpened bands.

We experienced the worst performance with LDFA with the original bands: precision was only 0.285 for the shadowed red tiles. Pansharpening improved it to a relevant degree; the new outcome with pan-sharpened bands became 0.833 and an increase was observed in each class (see Tables 4 and 5). RF and QDFA had similar results with three categories, and QDFA performed better with the original bands, the application of the pan-sharpened images resulting in a 4.7 per cent better performance. This result was somewhat below the best classification with three classes.

\section{Evaluation of pan-sharpening and classification performance}

According to the evaluation of the indices of accuracy assessment by the performance of classifiers in identifying the different roofing materials, we can observe that brown tiles usually fell outside 95 per cent accuracy (4 occurrences), while red tiles and asbestos had only one and two occurrences, respectively (Figure 7). Along the sensitivity and precision indices LDFA's performance was the worst, with five occurrences outside the 95 per cent limit, but the relatively good RF and QDFA also had two and one occurrences, respectively. Furthermore, pan-sharpened images were the most accurate considering thematic accuracy, only one occurrence was outside the 95 per cent quadrant. Sensitivity measures were usually higher than precision, ranging from 0.93 , while precision had the lowest value at 0.82 .

From another point of view, plotting the accuracy assessment indices along the original and pan-sharpened bands, we observed that pan-sharpened images were clustered in the upper 95 per cent quadrant (Figure 8) with only two exceptions. The range and the ratio of indices outside the 95 per cent limit were higher in the case of original bands, too.

\section{Discussion}

In total we built 12 types of model and their performance varied by their efficiency in discriminating the 3 or 6 classes using the original or pan-sharpened satellite bands (Figure 9). The first eight classifications had an OA higher than 95 per cent.

Considering the classified outputs (see Figures 5 and 6), we can spot error generated from misclassifications visually, i.e. salt and pepper appearance of different roofing classes within a dominant patch of roofs. This phenomenon is acceptable in pixelbased techniques and should be ignored in the interpretation.

Multiple Discriminant Function Analysis is a common classifier in remote sensing, but its usage is overshadowed by robust machine learning techniques; thus, nowadays this technique is not a common one in this filed. Several authors applied it but usually used its extensions or modifications (CHHIKARA, R.S. and Odell, P.L. 1973; Switzer, P. 1980; Du, Q. and Nekovei, R. 2005; Du, Q. and Younan, N. 2008; Wina, Herwindiati, D.E. and Isa, S.M. 2014). Authors sometimes apply ordination techniques (e.g. Principal Component Analysis) as a data preparation method prior to DFA to eliminate the issues raised by multicollinearity or, when using hyperspectral images, to reduce the number variables (BANDos, T.V. et al. 2009); however, we did not mix the two types of dimension reduction, following Martínez, A.M. and KaK, A.C. (2001). 


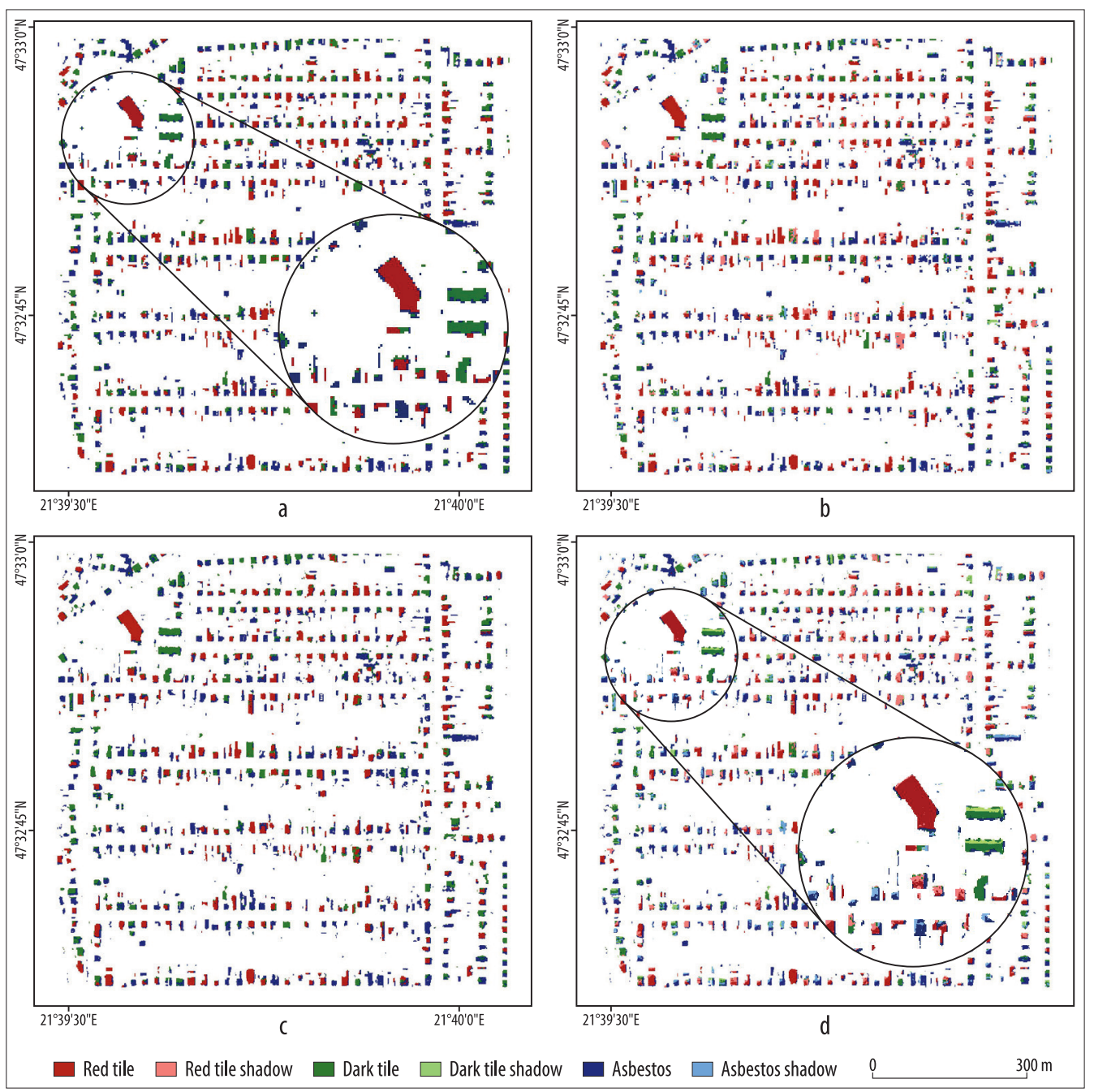

Fig. 5. Classified roofs of the study area with Linear Discriminant Function Analysis. $-\mathrm{a}=$ original bands with 3 classes; $\mathrm{b}=$ with 6 classes; $\mathrm{c}=$ pan-sharpened bands with 3 classes; $\mathrm{d}=$ with 6 classes

The linear type of Discriminant Analysis we applied is one of the most basic types and its performance was below the quadratic type and RF classifiers (see Figure 9). However, we must point out that even the worst result $(84.8 \%)$ with the six categories reached the desired 80 per cent OA (ESRI, 1994). Nevertheless, although LDFA performed well, QDFA provided better thematic accuracy, both in the case of original or pan-sharpened bands, a result reported by other authors, too (THARwAT, A. 2016; SiqueIRA, L.F.S. et al. 2017). However, we can find exceptions, when the two types of DFA perform almost identically (HALLOUCHE, F. et al. 1993; Manickavasagan, A. et al. 2008; VAdivambal, R. et al. 2010). Our results support the findings of studies revealing the better performance of QDFA: the second-best result was gained by QDFA with 3 classes. 


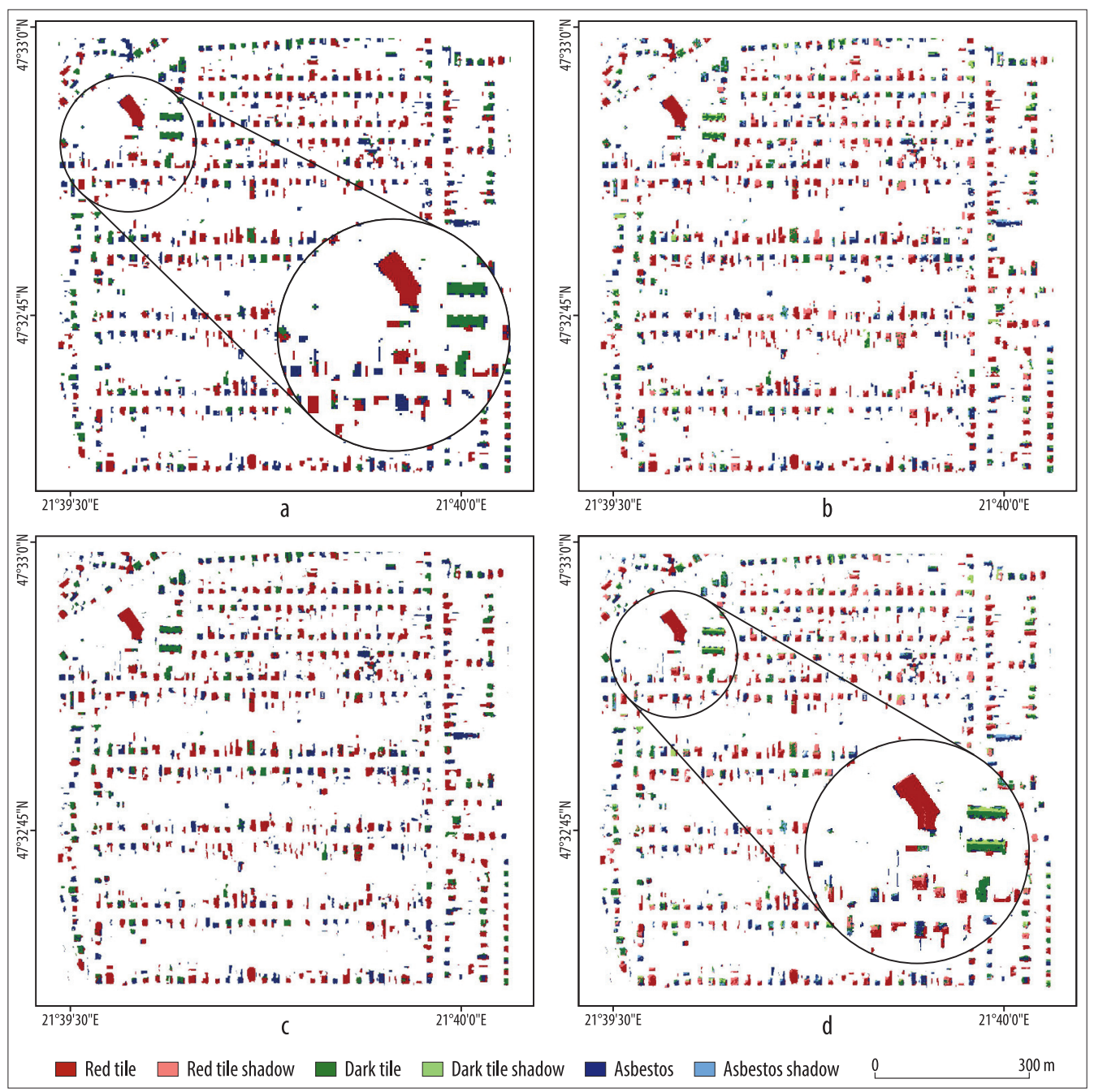

Fig. 6. Classified roofs of the study area with Random Forest $-\mathrm{a}-\mathrm{d}=$ For explanation see Fig 5.

LDFA's best performance was only the $5^{\text {th }}$ in the ranking. Both types of discriminant function classifiers were outperformed by the RF.

RF classifier resulted in good thematic accuracy from the applied algorithms, regardless of the number of classifiers. Sometimes it also provided weaker results with the original bands, but when the spatial resolution was increased, all indices of classification performance were above 95 per cent, and mostly above 98 per cent, indicating efficiency and robustness, as the distribution of the variables (i.e. bands) were not normal. Although we can find examples of a weaker performance of RF than other machine learning methods such as Support Vector Machine or Artificial Neural Networks (Statnikov, A. et al. 2008; PrančKevicius, T. and Marcinkevičius, V. 2017), we have to note that the difference between them 


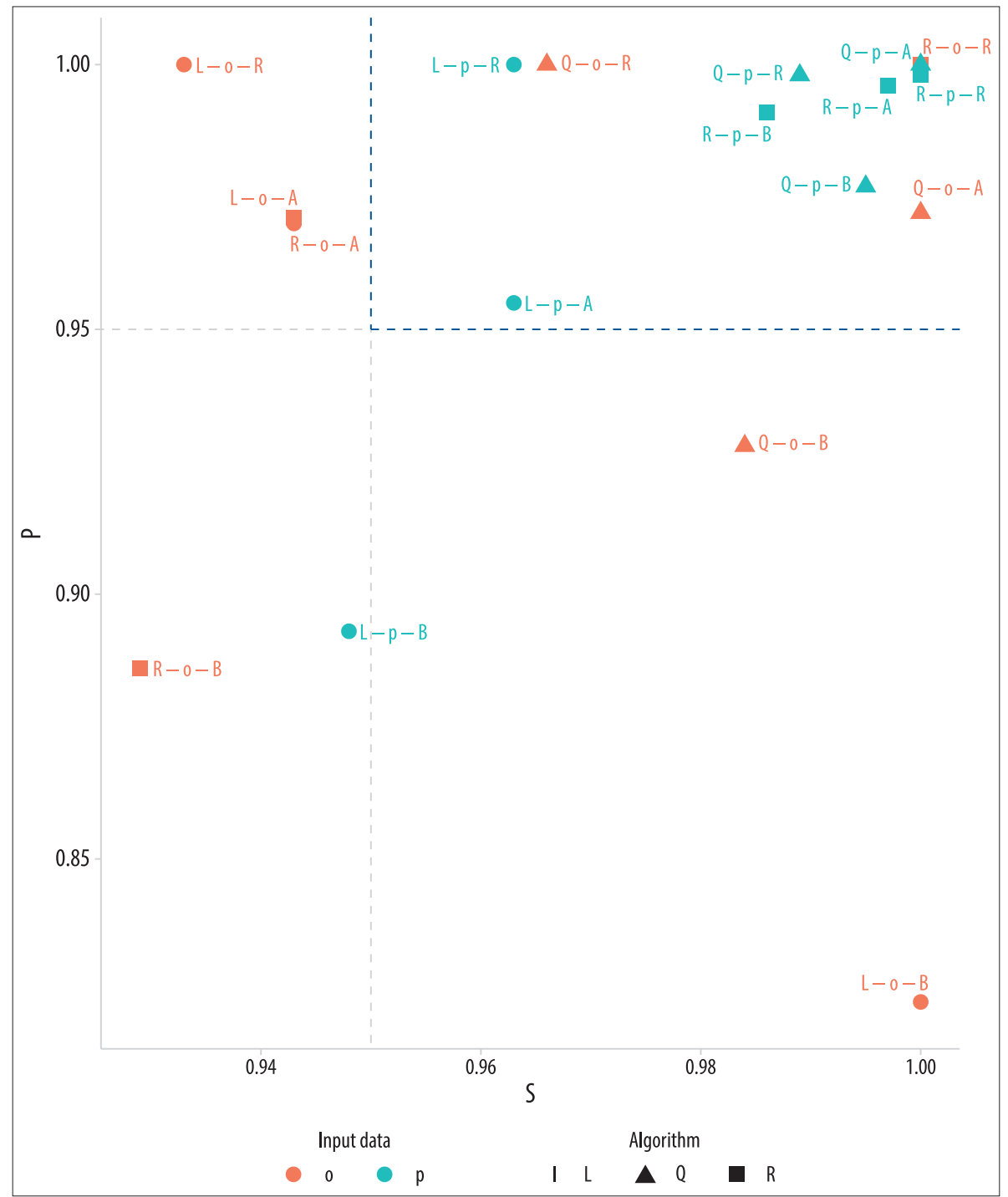

Fig. 7. Thematic accuracy based on Sensitivity $(\mathrm{S})$ and Precision $(\mathrm{P})$, highlighting the upper 95 per cent quadrant. - First letter of the labels: $\mathrm{L}=\mathrm{LDFA} ; \mathrm{Q}=\mathrm{QDFA} ; \mathrm{R}=\mathrm{RF}$. Second letter: $\mathrm{o}=$ original bands; $\mathrm{p}=$ pan-sharpened bands. Third letter: $\mathrm{A}=$ asbestos; $\mathrm{B}=$ brown tile; $\mathrm{R}=$ red tile

was below 3-5 per cent and it was considerably low only in some cases (RAсZKо, E. and ZaGajeWsKi, B. 2017).

These outcomes were the results of classifications conducted on only two classes (i.e. true/false), but when we include more classes RF can outperform the other classifiers (FERnÁNDEZ-Delgado, M. et al. 2014; BALÁzs, B. et al. 2018). In this case, RF was very efficient; nevertheless, the comparison revealed that QDFA can be very efficient, too. Considering the rank of the resampled OAs, 


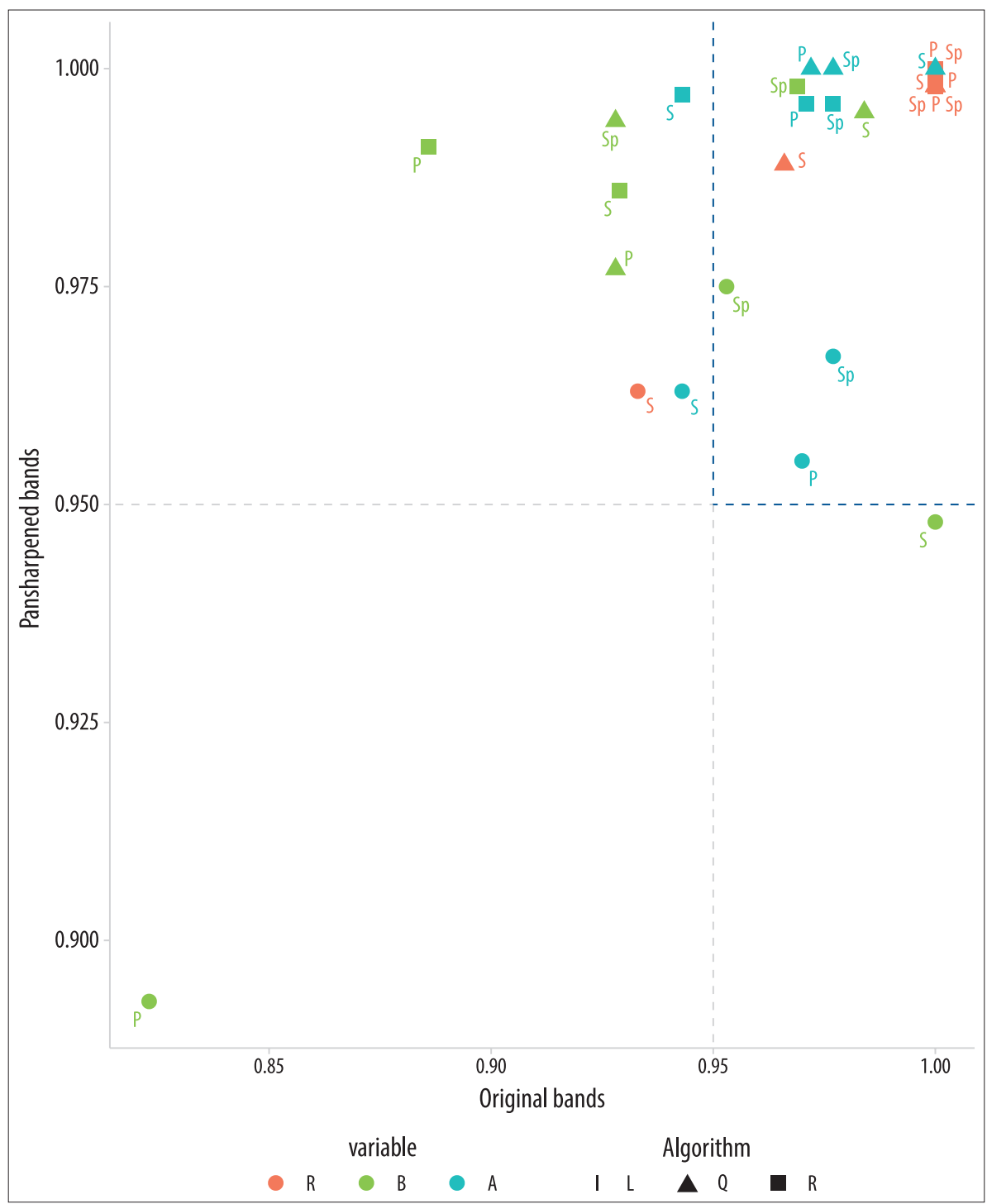

Fig. 8. Thematic accuracy based on the types of the bands involved, highlighting the upper 95 per cent quadrant - S, P, L, Q, R and coloured circles A, B and R = for explanation see Fig 7.

the most important result is that RF also performed well, both with three and six classes (see Figure 9), and except for the RF there was no other classifier in the first half of the ranking regarding the models of six classes which could achieve an OA as high as RF. Another important observation is the small range of 95 per cent confidence of RF with both three and six classes; thus, the reliability of the results was also excellent.

Most of the results can be explained by the advantages of pan-sharpening. Roofs have 


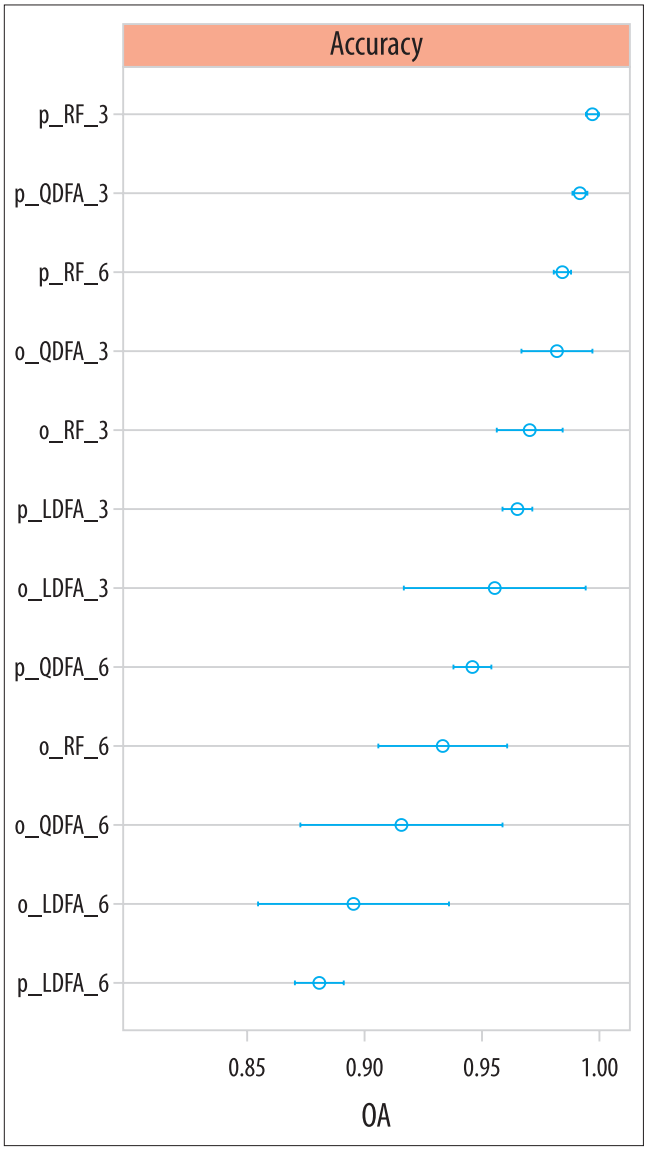

Fig. 9. Decreasing rank of Overall Accuracy (OA) of the applied classifiers. - $\mathrm{o}=$ original bands; $\mathrm{p}=$ pan-sharpened bands; LDFA = Linear Discriminant Function Analysis; QDFA = Quadratic Discriminant Function Analysis; RF = Random Forest; 3 or $6=$ number of classes

large surfaces but also have several roof planes depending on the geometry types (e.g. flat, gable, pyramid hip, mansard etc.) and all roof planes can have different spectral profiles. In the studied area the roof area of most houses is about $100 \mathrm{~m}^{2}$, and the most common geometry types are pyramid and gable roofs. Geometry can be more complex when cross gabled or cross hipped roofs or gable roofs are combined with valley roofs. Furthermore, these roof planes are fractioned with dormer windows, skylights, roof windows, chimneys or different vents. Therefore, the probability that reflectance of a $2 \times 2 \mathrm{~m}$ pixel is biased by roof plane geometry is very high. Besides, this $4 \mathrm{~m}^{2}$ pixel does not necessarily cover only the roof; it is also probable that the reflectance of the roofs and the surroundings of the roofs constitute the spectral profile. Accordingly, when we improve the geometric resolution to $0.5 \mathrm{~m}$ with the pansharpening procedure, the resultant pixel's area will be $0.25 \mathrm{~m}^{2}$.

Although several authors have reported that pan-sharpening alters the spectral consistency (Alparone, L. et al. 2004; Ehlers, M. et al. 2010), РАDwick, C. et al. (2010) developed a method to overcome this issue for WV-2 satellite images. We also found that there was no statistical difference between the original and pan-sharpened bands considering the reference database. Furthermore, we achieved the best results with the pansharpened input bands: out of the best six classifications five were with pan-sharpened bands, and only QDA had sufficient accuracy to reach $4^{\text {th }}$ place.

Considering the class-level accuracy measures, we revealed that brown tiles were outside the 95 per cent accuracy quadrat. From the perspective of classification, this shows that the spectral features were similar to the asbestos roofing materials; nevertheless, asbestos had smaller issues with misclassification (see Figures 7 and 8). Previous studies produced different results regarding the identification of roofing materials. In the work of SzABó, S. et al. (2014) the OA was between $60-80$ per cent, and the asbestos was identified with accuracies of 23-98 per cent (considering error omission and commission) with different approaches, which is worse than the accuracy achieved in this study, although they applied 10 classes of roofing types. The results of AвRIHA, D. (2017) were similar; he achieved 66-79 per cent accuracy in roof identification, and the asbestos was identified with an accuracy of 67-100 per cent. In this case, the discrimination of shadowed and sunny roof parts was 
ambiguous: while the sunny asbestos roof segments were identified with 98-100 per cent accuracy, in the case of shadowed parts the omission error was high (72\%). BARAKAT, D. et al. (2017) developed a rule-based method and achieved 93 per cent OA in asbestos identification with WV-2 data. KRówCZYŃsKA, M. et al. (2016) achieved 95 per cent OA with hyperspectral data, but the asbestos identification was biased by 38 per cent omission and 27 per cent commission errors.

Although the investigation was performed within a small study area, the method can be regarded as a general methodology: data collection, modelling and accuracy assessment can be generalized and applied in any types area regardless of the extent. Furthermore, traditional statistical analysis or machine learning can provide valuable data for all types of geographical analyses (e.g. Allen, C. et al. 2016; SzABó, Z. et al. 2017; BALÁzs, B. et al. 2018; ENYEDI, P. et al. 2018). Our study focused on image classification, but the procedure also works with tabular data. In our case the large number of roofs identified, and the careful segmentation of the roof planes yielded the relatively high accuracy. However, it is not a general panacea as the outcome depends on the reference data. This can be promising for municipalities when they decide to refine roof registers based on remotely sensed data, as satellite images are cheaper than unique aerial hyperspectral surveys.

\section{Conclusions}

We conducted an analysis on a WorldView-2 satellite image with LDFA, QDFA and RF classifiers. We investigated the effect of the number of classes and the potential efficiency of pan-sharpening. Our results revealed that: - discriminating the shadowed and sunny roof tiles did not improve the classification accuracy: results were up to 6-7 per cent worse when compared to the simple approach where the training dataset contained both the shadowed and sunny pixels;
- pan-sharpening was an effective technique to improve the classifications: it usually caused a 2-3 per cent better overall accuracy, but in the case of RF with the six classes the improvement was 10 per cent;

- regarding the classification algorithms, all of them performed well, but the best results were gained with Random Forest; besides, Random Forest was the most effective classifier with six classes;

- DFA-techniques performed better with fewer classes and QDFA outperformed LDFA;

- the resampling technique with the 10-fold cross-validation is an effective tool for the comparison of different classifiers.

Acknowledgement: The research was supported by the European Union and the State of Hungary, co-financed by the European Regional Development Fund (EFOP3.6.1-16-2016-00022) and the TNN 123457 project. AвriHA, D. was supported by the ÚNKP-18-2-I-DE-81 New National Excellence Program of the Ministry of Human Capacities.

\section{REFERENCES}

AвRIHA, D. 2017. Roofing material determination with hyperspectral data. Student V4 Geoscience Conference and Scientific Meeting GISÁČEK, Ostrava, Czech Republic, 5-10.

Allen, C., Tsou, M-H., Aslam, A., Nagel, A. and Gawron, J-M. 2016. Applying GIS and Machine Learning Methods to Twitter Data for Multiscale Surveillance of Influenza. PLoS ONE 11. (7): e0157734. https://doi.org/10.1371/journal.pone.0157734

Alparone, L., Baronti, S., Garzelli, A. and Nencini, F. 2004. A global quality measurement of pansharpened multispectral imagery. IEEE Geoscience and Remote Sensing Letters 1. (4): 313-317.

Balázs B., Bíró, T., Dyke, G., Singh, K. and Szabó, Sz. 2018. Extracting water-related features using reflectance data and principal component analysis of Landsat images. Hydrological Sciences Journal 63. (2): 269-284.

Bandos, T.V., Bruzzone, L. and Camps-Valls, G. 2009. Classification of hyperspectral images with regularized linear discriminant analysis. IEEE Transactions on Geoscience and Remote Sensing 47. (3): 862-873.

Barakat, M.A., Shafri, H.Z.M. and Hamedianfar, A. 2017. New semi-automated mapping of asbestos cement roofs using rule-based object-based image analysis and Taguchi optimization technique from WorldView-2 images. International Journal of Remote Sensing 38. (2): 467-491. 
Breiman, L. 2001. Random Forests. Machine Learning 45. (1): 5-32.

BrownleE, J. 2016. Machine Learning Mastery with R. Get Started, Build Accurate Models and Work Through Projects Step-by-Step. First edition, Machine Learning Mastery. https://machinelearningmastery. com/machine-learning-with-r/

Burai, P., LénÁrt, Cs., Valkó, O., Bekő, L., Szabó, Zs. and DEÁK, B. 2016. Fátlan vegetációtípusok azonosítása légi hiperspektrális távérzékelési módszerrel (Vegetation mapping in an alkali landscape - application of airborne hyperspectral data). Tájökológiai Lapok 14. (1): 1-12. (In Hungarian)

Burai, P., Tomor, T., Beкő, L. and DeÁk, B. 2015. Airborne hyperspectral remote sensing for identification grassland vegetation. ISPRS Annals of the Photogrammetry, Remote Sensing and Spatial Information Sciences 40. (3): 427-431. Doi: 10.5194/isprsarchives-XL-3-W3-427-2015

Chhikara, R.S. and Odell, P.L. 1973. Discriminant analysis using certain normed exponential densities with emphasis on remote sensing application. Pattern Recognition 5. (3): 259-272.

Cilia, C., Panigada, C., Rossini, M., Candiani, G., Pepe, M. and Colombo, R. 2015. Mapping of Asbestos Cement Roofs and Their Weathering Status Using Hyperspectral Aerial Images. ISPRS International Journal of Geo-Information 4. (2): 928-941.

Comber, A.J., Fisher, P., Brunsdon, C. and Khmag, A. 2012. Spatial analysis of remote sensing image classification accuracy. Remote Sensing of Environment 127. 237-246. Doi:10.1016/j.rse.2012.09.005

Congalton, R.G. 1991. A review of assessing the accuracy of classifications of remotely sensed data. Remote Sensing of Environment 37. 35-46.

Deák, M., Telbisz, T., Árvai, M., Mari, L., Horváth, F., Конán, B., Szabó, O. and Kovács, J. 2017. Heterogeneous forest classification by creating mixed vegetation classes using EO-1 Hyperion. International Journal of Remote Sensing 38. (18): 5215-5231.

Du, Q. and Nekovei, R. 2005. Implementation of real-time constrained linear discriminant analysis to remote sensing image classification. Pattern Recognition 38. (4): 459-471.

Du, Q. and Younan, N.H. 2008. Dimensionality Reduction and Linear Discriminant Analysis for Hyperspectral Image Classification. In Knowledge-Based Intelligent Information and Engineering Systems. Eds.: LovreK, I., Howlett, R.J. and JAIN, L.C., KES 2008. Lecture Notes in Computer Science 5179. 392-399.

Ehlers, M., Klonus, S., Åstrand, P.J. and Rosso, P. 2010. Multi-sensor image fusion for pansharpening in remote sensing. International Journal of Image and Data Fusion 1. (1): 25-45.

Environmental Systems Research Institute, National Center for Geographic Information and Analysis, and The Nature Conservancy 1994. Accuracy Assessment Procedures: NBS/NPS Vegetation Mapping Program. Santa Barbara, CA, and Arlington, VA. Report prepared for the National Biological Survey and National Park Service, Redlands.

Enyedi, P., PaP, M., Kovács, Z., TAKÁcs-Szilágyi, L. and Szabó, S. 2018. Efficiency of local minima and GLM techniques in sinkhole extraction from a LiDAR-based terrain model. International Journal of Digital Earth, online version: https://doi.org/10.1 080/17538947.2018.1501107

EüM-KöM 2000. EüM-KöM decree on the limitations of the activities with dangerous materials and products. Magyar Közlöny 41. 125. (In Hungarian)

Fernández-Delgado, M., Cernadas, E., Barro, S. and Amorim, D. 2014. Do we need hundreds of classifiers to solve real world classification problems? Journal of Machine Learning Research 15. 3133-3181. Gibril, M.B.A., Shafri, H.Z.M. and Hamedianfar, A. 2016. New semi-automated mapping of asbestos cement roofs using rule-based object-based image analysis and Taguchi optimization technique from WorldView-2 images. International Journal of Remote Sensing 38. (2): 467-491.

Gulácsi, A. and Kovács, F. 2018. Drought monitoring of forest vegetation using MODIS-based normalized difference drought index in Hungary. Hungarian Geographical Bulletin 67. (1): 29-42.

Hallouche, F., Adams, A.E., Hinton, O.R., Surtees, D.P., Wadehra, V. and Sherbet, G.V. 1993. Discriminant analysis for classification of murine melanomas and human cervical epithelial cells. Analytical and Quantative Cytollogy and Histology 15. 50-60.

Hijmans, R.J. 2017. raster: Geographic Data Analysis and Modeling. $R$ package version 2.6-7. https://CRAN.Rproject.org/package $=$ raster

Ho, T.K. 1995. Random Decision Forests. Proceedings of the $3^{\text {rd }}$ International Conference on Document Analysis and Recognition, Montreal, QC, 14-16. August 1995. 278-282.

Kang, D., Myung, M-S., KIM, Y-K. and KIM, J-E. 2013. Systematic Review of the Effects of Asbestos Exposure on the Risk of Cancer between Children and Adults. Annals of Occupational and Environmental Medicine 25(1) 10. Doi: 10.1186/2052-4374-25-10.

Kassambara, A. 2018. Machine Learning Essentials: Practical Guide in R. $1^{\text {st }}$ edition. CreateSpace Independent Publishing Platform.

Krówczyńska, M., Wilk, E., Pabjanek, P., Zagajewski, B. and Meuleman, K. 2016. Mapping asbestoscement roofing with the use of APEX hyperspectral airborne imagery: Karpacz area, Poland - a case study. Miscellanea Geographica 20. (1): 41-46.

KsIĄŻEK, J. 2014. Methods for Detection of AsbestosCement Roofing Sheets. Geomatics and Environmental Engineering 8. (3): 59-76.

Kuhn, M., Wing, J., Weston, S., Williams, A., Keefer, C., Engelhardt, A., Cooper, T., Mayer, Z., Kenkel, B., R Core Team, Benesty, M., Lescarbeau, R., Ziem, 
A., Scrucca, L., Tang, Y., Canadan, C. and Hunt, T. 2018. caret: Classification and Regression Training. R package version 6.0-79. https://CRAN.R-project. org/package $=$ caret

Louppe, G., Wehenkel, L., Sutera, A. and Geurts, P. 2013. Understanding variable importances in forests of randomized trees. Proceedings of the $26^{\text {th }}$ International Conference on Neural Information Processing Systems 1. 431-439.

Mándi, A., Posgay, M., Vadász, P., Major, K., Rödelsperger, K., Tossavainen, A., Ungváry, G., Woitowitz, H.J., Galambos, E., Németh, L., Soltész, I., EgERvÁry, M. and BöszörménYi NAGY, G. 2000. Role of occupational asbestos exposure in Hungarian lung cancer patients. International Archives of Occupational and Environmental Health 73. 555-560.

Manickavasagan, A., Jayas, D.S. and White, N.D.G. 2008. Thermal imaging to detect infestation by Cryptolestes ferrugineus inside wheat kernels. Journal of Stored Products Research 44. (2): 186-192.

Martínez, A.M. and KAK, A.C. 2001. PCA versus LDA. IEEE Transactions on Pattern Analysis and Machine Intelligence 23. (2): 228-233.

Maurer, T. 2013. How to Pan-Sharpen Images Using the Gram-Schmidt Pan-Sharpen Method - a Recipe. International Archives of the Photogrammetry, Remote Sensing and Spatial Information Sciences XL-1/W1. 239-244.

Mucsi, L., Liska, Cs.M., Henits, L., Товак, Z., Csendes, B. and Nagy, L. 2017. The evaluation and application of an urban land cover map with image data fusion and laboratory measurements. Hungarian Geographical Bulletin 66. (2): 145-156.

Nagyváradi, L., Gyenizse, P. and Szebényi, A. 2011. Monitoring the changes of a suburban settlement by remote sensing. Acta Geographica Debrecina Landscape and Environment 5. 76-83.

Padwick, C., Deskevich, M., Pacifici, F. and Smallwood, S. 2010. WorldView-2 Pan-Sharpening. Proceedings of ASPRS 2010 Annual Conference, San Diego, CA, USA, 26-30.

PAL, M. 2005. Random forest classifier for remote sensing classification. International Journal of Remote Sensing 26. 217-222.

Pásztor, L., Laborczi, A., TAKács, K., Szatmári, G., Dobos, E., Illés, G., Bakacsi, Zs. and Szabó, J. 2015. Compilation of novel and renewed, goal oriented digital soil maps using geostatistical and data mining tools. Hungarian Geographical Bulletin 64. (1): 49-64.

Petja, P.M., Twumasi, Y.A., Tengbeh, G.T. and Atanasova, M. 2010. Spatial epidemiology risk assessment for rehabilitated former asbestos mining areas in Limpopo Province, South Africa, using remote sensing and conventional analytical methods. South African Journal of Epidemiology and Infection 25. 32-39.
Podani, J. 2000. Introduction to the Exploration of Multivariate Biological Data. Leiden, Backhuys Publisher.

Powers, D.M.W. 2007. Evaluation: From Precision, Recall and F-Factor to ROC, Informedness, Markedness $\mathcal{E}$ Correlation. Technical Report SIE-07-001. Adelaide, South Australia. School of Informatics and Engineering, Flinders University Adelaide.

Pranckevičius, T. and Marcinkevičius, V. 2017. Comparison of Naive Bayes, Random Forest, Decision Tree, Support Vector Machines, and Logistic Regression Classifiers for Text Reviews Classification. Baltic Journal of Modern Computing 5. (2): 221-232.

Raczko, E. and Zagajewski, B. 2017. Comparison of support vector machine, random forest and neural network classifiers for tree species classification on airborne hyperspectral APEX images. European Journal of Remote Sensing 50. (1): 144-154.

R Core Team 2018. R: A language and environment for statistical computing. Vienna, R Foundation for Statistical Computing. https://www.R-project.org/

Rouse, J.W. Jr., HaAs, R.H., Deering, D.W., Schell, J.A. and Harlan, J.C. 1974. Monitoring the Vernal Advancement and Retrogradation (Green Wave Effect) of Natural Vegetation. NASA/GSFC Type III Final Report, Greenbelt, MD.

SAmsudin, S.H., Shafri, H.Z.M. and Hamedianfar, A. 2016. Development of spectral indices for roofing material condition status detection using field spectroscopy and WorldView-3 data. Journal of Applied Remote Sensing 10(2) 025021. Doi: 10.1117/1. JRS.10.025021

Siqueira, L.F.S., Araújo Júnior, R.F.A., de Araújo, A.A., Morais, C.L.M. and Lima, K.M.G. 2017. LDA vs. QDA for FT-MIR prostate cancer tissue classification. Chemometrics and Intelligent Laboratory Systems 162. 123-129.

Statnikov, A., Wang, L. and Aliferis, C. 2008. A comprehensive comparison of random forests and support vector machines for microarray-based cancer classification. BMC Bioinformatics 9. 319. Doi:10.1186/1471-2105-9-319

Stevens, J. 1996. Applied multivariate statistics for the social sciences. $3^{\text {rd }}$ edition. Mahwah, NJ, USA, Lawrence Erlbaum.

Switzer, P. 1980. Extensions of linear discriminant analysis for statistical classification of remotely sensed satellite imagery. Journal of the International Association for Mathematical Geology 12. (4): 367-376.

Szabó, S., GÁcsi, Z. and BALÁzs, B. 2016. Specific features of NDVI, NDWI and MNDWI as reflected in land cover categories. Acta Geographica Debrecina Landscape and Environment 10. (3-4): 194-202.

Szabó, Sz., Burai, P., Kovács, Z., Szabó, Gy., Kerényi, A., Fazekas, I., Paládi, M., Buday, T. and Szabó, G. 2014. Testing of algorithms for the identification of asbestos roofing based on hyperspectral data. 
Environmental Engineering and Management Journal 143. (11): 2875-2880.

Szabó, Z., Tóth, C.A., Tomor, T. and Szabó, S. 2017. Airborne LiDAR point cloud in mapping of fluvial forms: a case study of a Hungarian floodplain. GIScience and Remote Sensing 54. 862-880.

TAHERZADEh, E. and ShAFri, H.Z.M. 2013. Development of a Generic Model for the Detection of Roof Materials Based on an Object-Based Approach Using WorldView-2 Satellite Imagery. Advances in Remote Sensing 2. (4): 312-321.

TAHERZADEH, E., SHAFri, H.Z.M. and SHAHI, K. 2014. Roof Material Detection Based on Object-Based Approach Using WorldView-2 Satellite Imagery. International Journal of Environmental and Ecological Engineering 8. (10): 1826-1829.

TharWat, A. 2016. Linear vs. quadratic discriminant analysis classifier: a tutorial. International Journal of Applied Pattern Recognition 3. (2): 145-180.

Therneau T. and AtKinson, B. 2018. rpart: Recursive Partitioning and Regression Trees. $R$ package version 4.1-13. https://CRAN.R-project.org/package=rpart

Vadivambal, R., Vellaichamy, C., Jayas, D.S. and White, N.D.G. 2010. Detection of Sprout-Damaged Wheat Using Thermal Imaging. Applied Engineering in Agriculture 26. 999-1004.
Venables, W.N. and Ripley, B.D. 2002. Modern Applied Statistics with S. Fourth edition. New York, Springer.

Wiскнам, H. 2017. Tidyverse: Easily Install and Load the 'Tidyverse'. $R$ package version 1.2.1. https://CRAN.Rproject.org/package=tidyverse

Wilk, E., Krówczrńska, M. and Pabjanek, P. 2015. Determinants influencing the amount of asbestoscement roofing in Poland. Miscellanea Geographica 19. (3): $82-86$.

Wina, Herwindiati, D.E. and Isa, S.M. 2014. Robust discriminant analysis for classification of remote sensing data. International Conference on Advanced Computer Science and Information System, Jakarta, 18-19. Oct. 2014. Jakarta, IEEE Indonesia Section, 454-458.

Yuhendra, Alimuddin, I., Sumantyo, J.T.S. and Kuze, H. 2012. Assessment of pan-sharpening methods applied to image fusion of remotely sensed multi-band data. International Journal of Applied Earth Observation and Geoinformation 18. 165-174. 